\title{
When and How Should We Test the Tightness of the Vesicourethral Anastomosis after Retropubic Radical Prostatectomy?
}

\author{
A. Mattei S. Z'Brun P. Stucki G.B. Di Pierro \\ Klinik für Urologie, Luzerner Kantonsspital, Luzern, Switzerland
}

H. Danuser

\section{Key Words}

Retropubic radical prostatectomy - Prostate cancer •

Vesicourethral anastomosis $\cdot$ Cystography $\cdot$ Extravasation

\section{Introduction}

In case of a non-tight vesicourethral anastomosis (VUA) after radical prostatectomy (RP) the risk of a healing disturbance of the anastomosis and stricture formation is increased [1-3]. On the other hand, early removal of the bladder catheter improves the patient's comfort and results in earlier discharge from the hospital [4-9]. Therefore, it seems appropriate to leave the bladder catheter in place until the VUA is tight [10]. Interestingly, some institutions leave the bladder catheter in situ for 10-15 days knowing that significant extravasation is common until POD 5 to 8 [11-15]. Most groups perform a cystography at least in the anterior-posterior plane before they remove the catheter $[9,12,16,17]$. Other surgeons perform a cystogram only in patients in which they are not satisfied with the integrity of the anastomosis, in case of clinical suspected leakages or of wide bladder neck reconstruction [18].

The objectives of this prospective study were first to determine how many patients had a tight VUA on POD 3, 6 and 9 after retropubic radical prostatectomy (RRP), and secondly to determine if an additional lateral view cystography provides more clinically significant information than the anterior-posterior view alone.

\section{KARGER \\ Fax +41613061234 E-Mail karger@karger.ch} www.karger.com

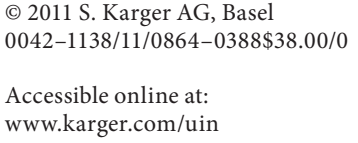




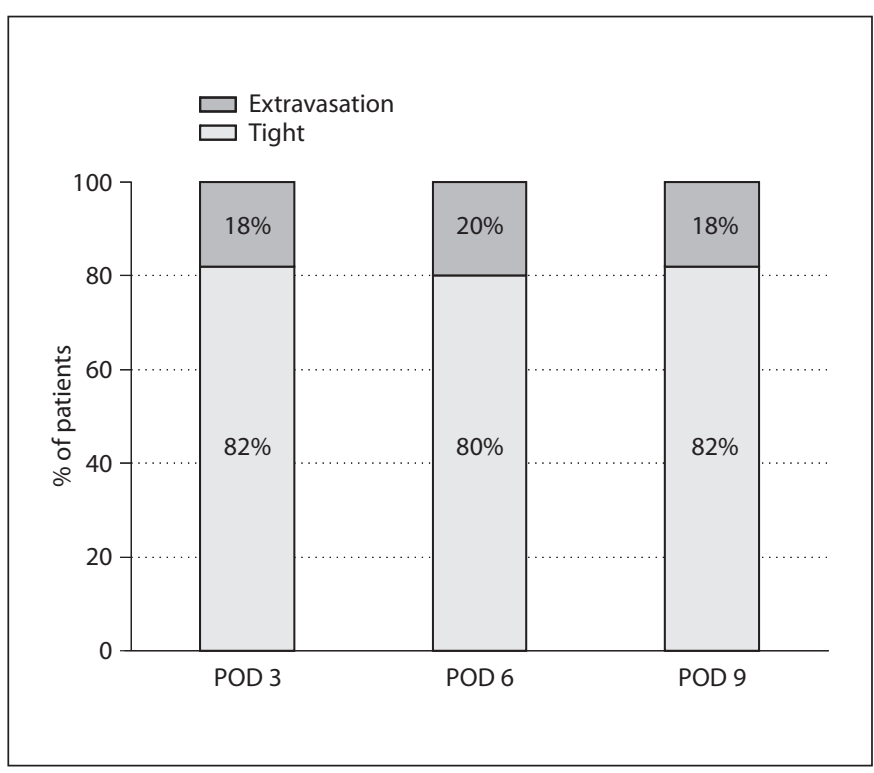

Fig. 1. Tightness of the VUA after retropublic radical prostatectomy on POD 3, 6 and 9.

Table 1. Patients' characteristics

\begin{tabular}{ll}
\hline $\begin{array}{l}\text { Number of patients (with complete follow-up) } \\
\text { Median age }\end{array}$ & $\begin{array}{l}100 \\
58 \text { years } \\
\text { (range } 48-76)\end{array}$ \\
$\begin{array}{ll}\text { Histopathological tumor stage } \\
\text { pT2 }\end{array}$ \\
pT3 & $17(82 \%)$ \\
pT4 & $1(1 \%)$ \\
Histopathologucal lymph node status & \\
pN0 & $87(87 \%)$ \\
pN+ & $13(13 \%)$ \\
Gleason score & \\
$2-4$ & $2(2 \%)$ \\
$5-7$ & $81(81 \%)$ \\
$8-10$ & $17(17 \%)$ \\
Attempted nerve sparing & $12(12 \%)$ \\
None & $35(35 \%)$ \\
Monolateral & $53(53 \%)$ \\
Bilateral & \\
\hline
\end{tabular}

\section{Patients and Methods}

One hundred and seven consecutive patients who underwent RRP and pelvic lymph node dissection (PLND) for organ-confined prostate cancer were included in the study. All patients were operated by 3 senior surgeons.

After meticulous lymph node dissection, particularly along the internal iliac vessels, the outer layer of the endopelvic fascia was sharply incised medially to the tendinous arc, leaving the puboprostatic ligaments untouched to ensure urethral stability. In case of attempted nerve sparing the neurovascular bundle was carefully rolled away from the lateral prostate after incision of the second layer of the endopelvic fascia, the periprostatic fascia. The deep Santorini's plexus was bunched and ligated over the apical prostate and at the bladder neck, and then transected over the ventral aspect of the prostate to avoid damage to the urethral sphincter. The prostatic apex was approached directly along the lateral side of the prostatic capsule and the urethra was transected sharply with scissors. The bladder was opened on the ventral side. After urine ejaculation allowed localization of the ureteral orifices the bladder neck was transected and the prostate was removed. Bladder neck sparing was not attempted. The bladder neck was reconstructed by a dorsal running seromuscular suture to $8-10 \mathrm{~mm}$ wide using a 2-zero polyglycolic acid. Six 2-zero polyglycolic acid sutures were placed and tied over an 18-Fr urethral silicon catheter without eversion of the bladder mucosa [19]. We routinely placed 2 pelvic 'easy flow' drains in the right and left fossa obturatoria during surgery, with removal when the drainage was $<50 \mathrm{ml} /$ day.

A pressure-controlled cystography (max. $20 \mathrm{~cm} \mathrm{H}_{2} \mathrm{O}$ ) with anterior-posterior and lateral view were performed on POD 3, 6 and 9. VUA was defined as non-tight by extravasation of any size. In case of a tight VUA or only a small extravasation (defined as less than half of the diameter of the 18-Fr bladder catheter), the bladder catheter was removed after the cystography on POD 9. In case of a more extensive extravasation, the bladder catheter was left in place and cystography was repeated on POD 15 or later if leakage persists. Patients received a single antibiotic dose with $2 \mathrm{~g}$ intravenous cefazolinum perioperatively. This study has been approved by our center ethics committee and conducted in accordance with the tenets of the Declaration of Helsinki. Written informed consent was obtained from the patients before inclusion.

\section{Results}

Complete follow-up is documented in 100 of 107 patients. Seven patients were excluded from the study by uncompleted cystographic follow-up. Patients' characteristics represent an average population for RRP and are described in table 1.

Eighty-two of 100 VUA were tight on POD 3, 80 were tight on POD 6 and 82 were tight on POD 9 (fig. 1). Median catheterization time was 9 days (range 9-18 days). Of the 18 patients with a non-tight VUA on POD 3, 3/18 (17\%) were tight on POD 6, 8/18 patients (44\%) on POD 9 and $2 / 18$ patients (11\%) on POD 15 . In 5 of the 18 patients $(28 \%)$ VUA showed only a small extravasation less than 2-3 mm on X-ray images on POD 9 and, nevertheless, the urethral catheter was removed (fig. 2a). Ninetyfive percent (78/82) of all VUA which were tight on POD 3 remained tight on POD 6 and 9. However, 4 of the 82 patients (5\%) who had a tight VUA on POD 3 showed ex- 


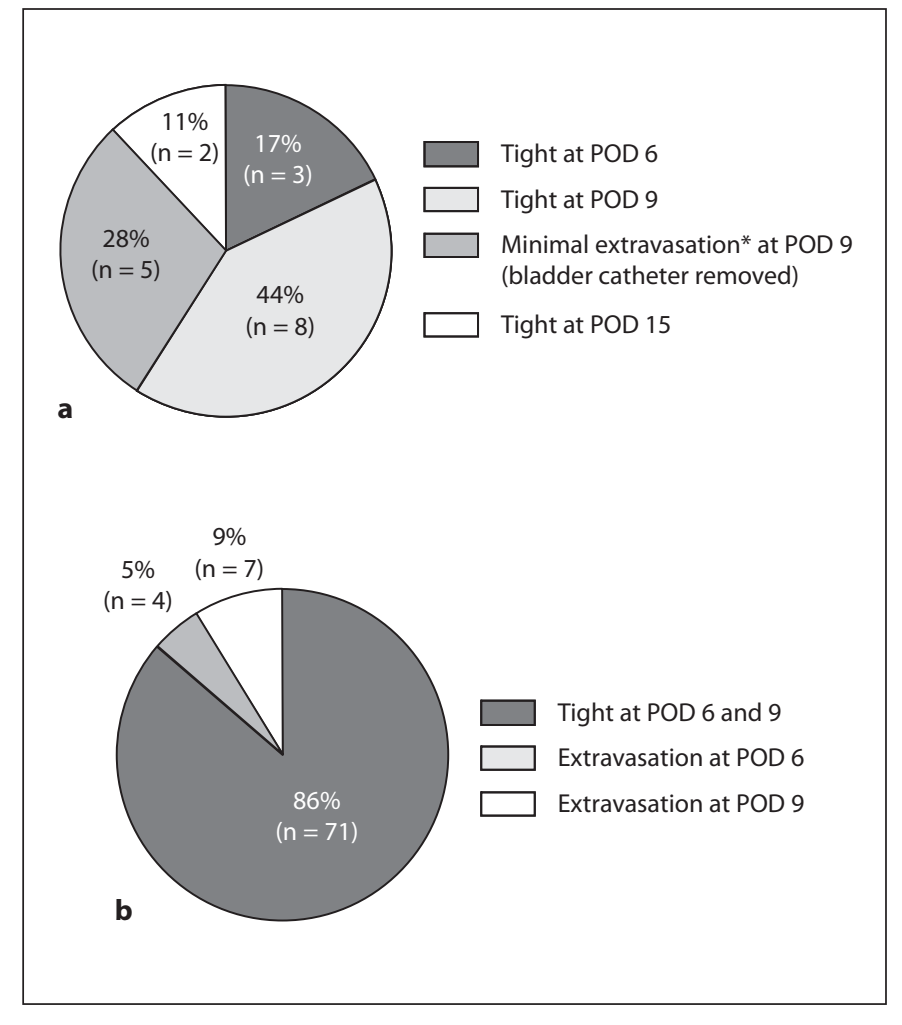

Fig. 2. a Outcome of 18 primary non-tight VUA on POD 3. * Defined as less than about half the diameter of the 18-Fr bladder catheter. b Outcome of primary tight VUA at POD $3(n=82)$.

travasation at cystography on POD 6 and 7 of the $82(9 \%)$ had extravasation in the cystography on POD 9 (fig. 2b). Two of 100 patients (2\%) showed a leakage on POD 15 and none on POD 18.

Of the total 300 performed cystographies, 52 (17\%) revealed extravasations. In 34 of 52 cystographies (65\%), the extravasation was recognized in the anterior-posterior as well as the lateral view. In 3 of 52 cystographies (6\%), the extravasation was seen only in the anterior-posterior images and in 15 (29\%) only in the lateral view (fig. 3). The instilled volume for pressure-controlled $\left(20 \mathrm{~cm} \mathrm{H}_{2} \mathrm{O}\right)$ cystography was median $110 \mathrm{ml}$ (range $30-250 \mathrm{ml}$ ) on POD 3, $120 \mathrm{ml}$ (range 40-230) on POD 6 and $110 \mathrm{ml}$ (range 35-230) on POD 9. The bladder capacity differences between POD 3 and 6, POD 6 and 9 as well as POD 3 and 9 were not significant.

At hospital discharge, the median residual volume after voiding was $0 \mathrm{ml}$ (range $0-80 \mathrm{ml}$ ). Two of the $100 \mathrm{pa}$ tients (2\%) were discharged with suprapubic bladder catheters in situ because of the inability to void spontaneously. The cystostomy catheters were removed 5 days lat-

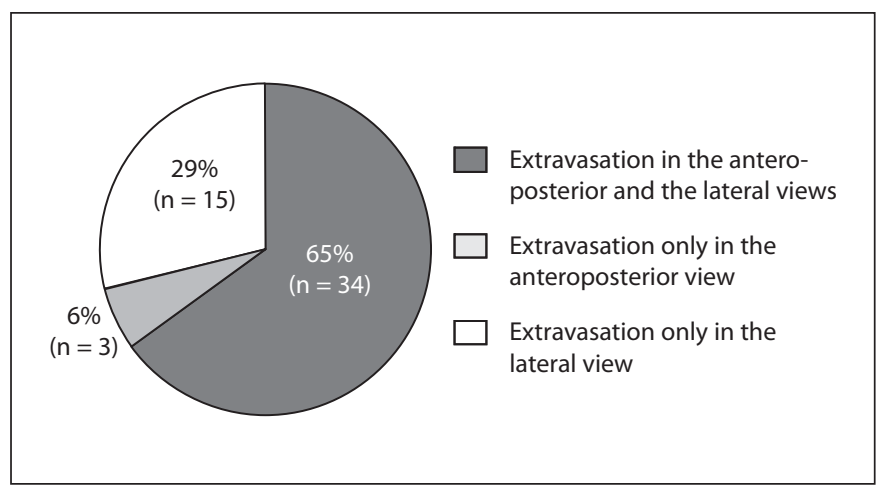

Fig. 3. Recognition of 52 extravasations in the anterior-posterior and the lateral view in over 300 cystographies performed in 100 patients.

er after anti-inflammatory therapy with diclofenac $50 \mathrm{mg}$ 3 times daily.

Three of the 100 patients (3\%) developed a stricture of the VUA 2 and 3 weeks and 3 months postoperatively. In 2 of the 3 patients who developed a stricture severe extravasations were diagnosed in the cystography on POD 3,6 and 9. Two strictures were dilated under local anesthesia and in 1 case incision and resection of scar tissue of the stricture were necessary. After resection, this patient developed substantial stress incontinence necessitating 2-3 pads per day.

There was no statistical correlation between leakage of the VUA and pathological tumor stage.

\section{Discussion}

Many studies describe the use of cystography following RRP for confirmation of a watertight VUA before removal of the bladder catheter $[9,12,16,17]$. These reports are quite variable regarding time of cystography and tightness rates. The presence of extravasations on cystography ranges between 4.6 and $25.9 \%[5,7,10-12,15-17$, 20]. Also, the time of the examination varies widely between POD 2 and POD 18 [5, 15]. Many authors emphasize the advantages of early catheter removal with shortening of the hospitalization time and increasing patient comfort [5, 7-10]. Tiguert et al. [5] reported improved continence related to early catheter removal, suggesting that the catheter may cause hypersecretion of the paraurethral glands which in turn may then enhance the risk of infection and interfere with the healing process. 
Huang and Lepor [10] found that the prevalence of anastomotic strictures is unrelated to the degree of urinary extravasation on cystography but reflects many factors, including surgical technique, surgeons experience, postoperative blood loss and peri-anastomostic hematoma.

The fact that a primary tight VUA became secondarily non-tight can be explained by the fact that tissue edema at POD 3 may mask leaks which became evident later. To our knowledge, this is the first prospective study documenting the evolution of VUA tightness during the early postoperative course and the usefulness of lateral view cystography to detect extravasations. Furthermore, previous studies usually do not supply information about volume and pressure during the cystography nor whether the cystography was performed in two planes. The test of the VUA tightness by pressure-controlled bladder filling $\left(20 \mathrm{~cm} \mathrm{H}_{2} \mathrm{O}\right)$ provides the advantage of evaluating extravasation such as a parameter related to a constant intravesical pressure in all the patients, regardless of bladder capacity.

Our results on the rate of VUA extravasation are similar to those already published, and this despite our diagnosis of extravasation being particularly accurate. In our study every recognizable extravasation of contrast in both radiological planes (anterior-posterior and lateral) was interpreted as such independent of size. Our cumulated rate of extravasations diagnosed on POD 3, 6 and 9 was $17 \%$. This would be reduced to $12 \%$ if only the extravasations recognized on the anterior-posterior view were considered.

Thus, the clinical relevance of performing cystographies in two planes does not seem to be evident. In fact, our rate of symptomatic strictures complications due to VUA nontightness is not really different from those of groups performing monoplanar cystography. Based on our experience, we can conclude that cystography only in the anterior-posterior view will miss a consistent number of extravasations but it seems to be sufficient for daily clinical practice. Small extravasations do not seem to influence the healing process of the VUA [13]. Probably, the clinical significance of minor leakages is irrelevant in most cases. However, significant extravasations seem to facilitate the formation of VUA strictures which then need further therapy. In fact, 2 of the 3 patients developing a stricture of the VUA in our study had significant extravasations during the entire early postoperative follow-up. In our opinion, the main limitation of the present study is its small patient number. In addition, over $80 \%$ of men had no demonstrable extravasation on the first cystography (POD 3), limiting in this way the number of patients with useful information to fewer than 20.

\section{Conclusion}

About $80 \%$ of the VUA are tight on POD 3. Of the tight VUA on POD 3, 5\% and 9\%, respectively, showed extravasations on POD 6 and 9. An additional lateral cystography discovers about 30\% more extravasations. Large extravasations might be a predisposition for a stricture formation. Because most VUA are already tight on POD 3 and 6 , and, because the clinical significance of minor leakages is probably irrelevant, the catheter can be removed in this lapse of time, although a small percentage of already tight VUA becomes nontight.

\section{References}

1 Poulakis V, Skriapas K, de Vries R, Dillenburg W, Witzsch U, Becht E: Vesicourethral anastomosis during endoscopic extraperitoneal radical prostatectomy: a prospective comparison between the single-knot running and interrupted technique. Urology 2006;68:1284-1289.

-2 Lieber D, Tran V, Belani J, Ames C, Morissey K, Yan Y, Humphrey P, Venkatesh R, Landman J: Comparison of running and interrupted vesicourethral anastomoses in a porcine model. J Endourol 2005;19:1109-1113.
- 3 De Stefani S, Sighinolfi MC, Mofferdin A, Paterlini M, Micali S, Celia A, Peluso G, Bianchi G: Transrectal contrast-enhanced (Levovist) ultrasonography in evaluation of urinary leakage after radical prostatectomy: a preliminary report. Urology 2005;66:871873.

-4 Nadu A, Salomon L, Hoznek A, Olsson LE, Saint F, de La Taille A, Cicco A, Chopin D, Abbou CC: Early removal of the catheter after laparoscopic radical prostatectomy. J Urol 2001;166:1662-1664.

5 Tiguert R, Rigaud J, Fradet Y: Safety and outcome of early catheter removal after radical retropubic prostatectomy. Urology 2004;63: 513-517.
6 Patel R, Lepor H: Removal of urinary catheter on postoperative day 3 or 4 after radical retropubic prostatectomy. Urology 2003;61: 156-160.

-7 Souto CA, Telöken C, Souto JC, Rhoden EL, Ting HY: Experience with early catheter removal after radical retropubic prostatectomy. J Urol 2000;163:865-866.

$\checkmark 8$ Koch MO, Nayee AH, Sloan J, Gardner T, Wahle GR, Bihrle R, Foster RS: Early catheter removal after radical retropubic prostatectomy: long-term follow-up. J Urol 2003; 169:2170-2172. 
$>9$ Lepor H, Nieder AM, Fraiman MC: Early removal of urinary catheter after radical retropubic prostatectomy is both feasible and desirable. Urology 2001;58:425-429.

10 Huang G, Lepor H: Factors predisposing to the development of anastomotic strictures in a single-surgeon series of radical retropubic prostatectomies. BJU Int 2006;97:255-258.

-11 Varkarakis J, Wirtenberger W, Pinggera GM, Berger A, Harabayashi T, Bartsch G, Horninger W: Evaluation of urinary extravasation and results after continence-preserving radical retropubic prostatectomy. BJU Int 2004;94:991-995.

-12 Ramsden AR, Chodak GW: Can leakage at the vesico-urethral anastomosis be predicted after radical retropubic prostatectomy? BJU Int 2004;93:503-506.
3 Leibovitch I, Rowland RG, Little JS Jr, Foster RS, Bihrle R, Donohue JP: Cystography after radical retropubic prostatectomy: clinical implications of abnormal findings. Urology 1995;46:78-80.

14 Guru KA, Seereiter PJ, Sfakianos JP, Hutson AD, Mohler JL: Is a cystogram necessary after robot-assisted radical prostatectomy? Urol Oncol 2007;25:465-467.

15 Schatzl G, Madersbacher S, Hofbauer J, Pycha A, Reiter WJ, Svolba G, Marberger M: The impact of urinary extravasation after radical retropubic prostatectomy on urinary incontinence and anastomotic strictures. Eur Urol 1999;36:187-190.

16 Lein M, Stibane I, Mansour R, Hege C, Roigas J, Wille A, Jung K, Kristiansen G, Schnorr D, Loening SA, Deger S: Complications, urinary continence, and oncologic outcome of 1,000 laparoscopic transperitoneal radical prostatectomies-experience at the Charité Hospital Berlin, Campus Mitte. Eur Urol 2006;50:1278-1282; discussion 1283-1284.
17 Williams TR, Longoria OJ, Asselmeier S, Menon M: Incidence and imaging appearance of urethrovesical anastomotic urinary leaks following da Vinci robotic prostatectomy. Abdom Imaging 2008;33:367-370.

18 Gnanapragasam VJ, Baker P, Naisby GP, Chadwick D: Identification and validation of risk factors for vesicourethral leaks following radical retropubic prostatectomy. Int J Urol 2005; 12:948-952.

19 Burkhard FC, Kessler TM, Fleischmann A, Thalmann GN, Schumacher M, Studer UE: Nerve sparing open radical retropubic prostatectomy-does it have an impact on urinary continence? J Urol 2006;176:189-195.

20 Coogan CL, Little JS, Bihrle R, Foster RS: Urethral catheter removal prior to hospital discharge following radical prostatectomy. Urology 1997;49:400-403. 